\title{
Ontogeny of pituitary thyrotrophs and regulation by endogenous thyroid hormone feedback in the chick embryo
}

\author{
Michael Muchow ${ }^{1,2}$, loannis Bossis ${ }^{1}$ and Tom E Porter ${ }^{1,2}$ \\ ${ }^{1}$ Department of Animal and Avian Sciences, University of Maryland, College Park, Maryland 20742, USA \\ ${ }^{2}$ Molecular and Cell Biology Program, University of Maryland, College Park, Maryland 20742, USA \\ (Requests for offprints should be addressed to T E Porter; Email: TEPorter@umd.edu)
}

\begin{abstract}
Increased thyroid hormone production is essential for hatching of the chick and for the increased metabolism necessary for posthatch endothermic life. However, little is known about the ontogeny and distribution of pituitary thyrotrophs during this period or whether pituitary thyroid-stimulating hormone (TSH) production is regulated by endogenous thyroid hormones during chick embryonic development. This study assessed the abundance and location of pituitary thyrotrophs and the regulation of TSH $\beta$ peptide and mRNA levels by endogenous thyroid hormones prior to hatching. TSH $\beta$-containing cells were first detected on embryonic day (e) 11, and the thyrotroph population increased to maximum levels on e17 and e19 and then decreased prior to hatching (d1). Thyrotroph distribution within the cephalic lobe of the anterior pituitary was determined on e19 by whole-mount immunocytochemistry for TSH $\beta$ peptide and by wholemount in situ hybridization for TSH $\beta$ mRNA. Thyrotroph
\end{abstract}

distribution within the cephalic lobe was heterogeneous among embryos, but most commonly extended from the ventral medial region to the dorsal lateral regions, along the boundary of the cephalic and caudal lobes. Inhibition of endogenous thyroid hormone production with methimazole (MMI) decreased plasma thyroxine $\left(\mathrm{T}_{4}\right)$ levels and increased pituitary TSH $\beta$ mRNA levels on e19 and $\mathrm{d} 1$. However, control pituitaries contained significantly more TSH $\beta$ peptide than MMI-treated pituitaries on e17 and e19, suggesting higher TSH secretion into the blood in MMI-treated groups. We conclude that thyrotroph abundance and TSH production increase prior to hatching, that thyrotrophs are localized heterogenenously within the cephalic lobe of the anterior pituitary at that time, and that TSH gene expression and secretion are under negative feedback regulation from thyroid hormones during this critical period of development.

Journal of Endocrinology (2005) 184, 407-416

\section{Introduction}

Thyroid hormones are involved in the regulation of growth, metabolism, heat production, gonadal development, molting, migration, and hatching in birds ( $\mathrm{McNabb}$ 2000). Thyroid-stimulating hormone (TSH) plays an important role in the hypothalamic-pituitary-thyroid (HPT) axis in mammals. However, due to a lack of homologous antisera to TSH in birds and the only recent description of an anti-peptide antibody (Iwasawa et al. 2002), the physiological role of TSH in the regulation of the HPT axis in avian species has not been intensively researched. Most of what has been learned about the biology of TSH secretion has been through the use of bioassays, heterologous antisera assays, and assays for the $\alpha$-subunit. Thyrotropin-releasing hormone (TRH) stimulates secretion of TSH-like bioactivity from pituitaries cultured in vitro (Scanes 1974), and increases plasma levels of thyroxine $\left(\mathrm{T}_{4}\right)$ in vivo (Kuhn et al. 1988). In addition to $\mathrm{TRH}$, corticotropin-releasing hormone $(\mathrm{CRH})$ has been shown to induce TSH release in chickens, and somatostatin can diminish the CRH- and TRH-induced TSH response through the type 2 and type 5 somatostatin receptors (Geris et al. 1996, 2003a,b, DeGroef et al. 2003). Thyroid-stimulating activity has been localized to the cephalic lobe of the anterior pituitary (Brasch \& Betz 1971, Radke \& Chiasson 1974, 1977), and cells containing immunoreactive TSH have been localized to the cephalic lobe in histological sections stained with antisera against mammalian TSH (Sharp et al. 1979, Thommes et al. 1983, Mikami 1986, Murphy \& Harvey 2001, 2002, Sasaki et al. 2003) or with an antiserum raised against a peptide based on the chicken TSH $\beta$ sequence (Iwasawa et al. 2002, Nakamura et al. 2004). Similarly, pituitary cells that stained with monoclonal antibodies against the chicken $\alpha$-subunit and that did not also stain with anti-chicken luteinizing hormone (LH) $\beta$ and follicle-stimulating hormone (FSH) $\beta$ monoclonal antibodies were localized to the cephalic lobe (Berghman et al. 1993). Thommes et al. (1983) reported that the thyrotrophs were first detectable 
on embryonic day (e) 6.5 and dramatically increased on e11.5, the time in embryonic development when the HPT axis is thought to become functionally mature in chickens (Thommes et al. 1983). However, Murphy \& Harvey $(2001,2002)$ found no immunoreactive TSH in the pituitary on e7, and Nakamura et al. (2004) first detected TSH-containing cells on e10. The $\alpha$-subunit mRNA is expressed as early as e3.5 (Kameda et al. 2000), while TSH $\beta$ mRNA levels are present from e9 and increase at the end of embryonic development (Gregory et al. 1998, Nakamura et al. 2004). Depression of plasma thyroid hormone levels by goitrogen administration has been shown to increase the size of purported thyrotrophs and the thyroid-stimulating bioactivity of the pituitary, suggesting that thyroid hormones exert negative feedback on TSH production in mature birds (Sharp et al. 1979), and treatment of e19 pituitary cells in vitro with triiodothyronine $\left(\mathrm{T}_{3}\right)$ significantly decreased levels of TSH $\beta$ mRNA (Gregory et al. 1998). However, nothing is known about the regulation of TSH protein production by endogenous thyroid hormones in the developing chick embryo, even though production of thyroid hormones is essential for hatching and progression to endothermic life. Pituitary TSH $\beta$ mRNA levels increase prior to hatching, coincident with an increase in plasma $T_{4}$ and $T_{3}$, raising the possibility that pituitary TSH production is free from the negative effects of thyroid hormones at this critical juncture of development. In the present study we validated an antiserum raised against purified rat $\operatorname{TSH} \beta$ subunit to detect chicken TSH $\beta$ peptide. This antiserum was used in immunocytochemistry, along with whole-mount in situ hybridization, to characterize the distribution of thyrotrophs within the cephalic lobe of the anterior pituitary and to quantify the abundance of thyrotrophs during embryonic development. Finally, TSH $\beta$ gene and peptide expression were examined following in vivo goitrogen treatment of developing embryos, to assess involvement of thyroid hormone negative feedback in controlling TSH production prior to hatching. We report that TSH $\beta$ gene expression and pituitary content are regulated by negative feedback from endogenous thyroid hormones by the end of chick embryonic development, even though levels of thyroid hormones, pituitary TSH gene expression, and pituitary thyrotrophs all increase prior to hatching. These findings suggest that hypothalamic feed-forward stimulation, rather than a lack of thyroid hormone negative feedback, is the predominant cause of the increased HPT axis activity at the end of embryonic development necessary for hatching and endothermic existence.

\section{Materials and Methods}

\section{Animals, incubations and injections}

All animals were Avian $\times$ Avian broiler strain chicken embryos obtained from Allen's Hatchery (Seaford, DE,
USA). Eggs were set in a humidified incubator at $37.5{ }^{\circ} \mathrm{C}$, and that day was designated as e0. Ethanol-swabbed eggs were injected with a sterile $1 \mathrm{ml}$ syringe by inserting the needle (25-gauge) into the albumen at the junction of the air cell, which was visualized by candling and marked. Chicken eggs received injections (in $100 \mu \mathrm{l}$ sterile water) of $125 \mu \mathrm{g}$ of the thyroid hormone synthesis inhibitor methimazole (MMI) on e13, $250 \mu \mathrm{g}$ on e15, $500 \mu \mathrm{g}$ on $\mathrm{e} 17$, and $750 \mu \mathrm{g}$ on e19. MMI doses were chosen based on preliminary studies that defined doses effective at suppressing development and hatching but which were nonlethal. Control eggs were injected with sterile water. Water was used as the vehicle because the injections were made into the water-containing albumen. The injection hole was sealed with cellophane tape. Animals were used with approval from our Institutional Animal Care and Use Committee.

\section{Western blotting}

Chicken pituitaries were isolated, pooled, and homogenized in either $0.1 \mathrm{M} \mathrm{HCl}$, or a protein extraction buffer (10\% glycerol, $15 \mathrm{mM}$ HEPES $\mathrm{pH} 7 \cdot 9,300 \mathrm{mM} \mathrm{NaCl}$, $50 \mathrm{mM} \mathrm{KCl}, 0.5 \%$ deoxycholate, $0.5 \%$ CHAPS, $0.5 \%$ Triton-X 100, 1 x proteinase inhibitor cocktail (Roche Molecular Biochemicals, Mannheim, Germany) and $2 \mathrm{mM}$ EDTA pH 8.0) in a $1 \mathrm{ml}$ Dounce homogenizer (Wheaton, Millville, NJ, USA). Protein concentrations in pituitary extracts were quantified by the bicinchoninic acid assay (Pierce; Rockford, IL, USA) according to manufacturer's directions and extracts were separated on a $12 \cdot 5 \%$ SDS-polyacrylamide gel using a Tris-Tricine-SDS running buffer under a current of $60 \mathrm{~mA}$. Proteins were transferred overnight to a $0 \cdot 45 \mu \mathrm{m}$ supported-nitrocellulose membrane (Bio-Rad; Hercules, CA, USA) using a $0 \cdot 2 \mathrm{M}$ phosphate buffer at $22 \mathrm{~V}$. The membrane was washed twice for $5 \mathrm{~min}$ in PBS ( $\mathrm{pH} \mathrm{7.4)}$ ) and then incubated for 30 min in $0.3 \% \mathrm{H}_{2} \mathrm{O}_{2}$ in PBS. The membrane was washed again for $5 \mathrm{~min}$ in PBS and then blocked with 1\% normal goat serum (NGS) for $1 \mathrm{~h}$. After blocking, the membrane was incubated with the rabbit anti-rat TSH $\beta$ antiserum (NIDDK-anti-rBetaTSH-IC-1) diluted 1:10000 in $0 \cdot 05 \%$ Tween 20-PBS (T-PBS) with 1\% NGS for $3 \mathrm{~h}$. The membrane was washed five times for 5 min with T-PBS and then incubated with a goat anti-rabbit biotinylated $\operatorname{IgG}$ secondary antibody (Vector Laboratories, Burlingame, CA, USA) in T-PBS with 1\% NGS for $2 \mathrm{~h}$. Again the membrane was washed 5 times for 5 min with T-PBS. After washing, the membrane was incubated with Vectastain ABC reagent (Vector Laboratories), an avidinbiotin signal amplification complex, for $30 \mathrm{~min}$. The membrane was washed again with PBS and developed using the Vectastain VIP horseradish peroxidase substrate kit (Vector Laboratories). When statistical tests were applied, bands were scanned and quantified using ImageQuant software (Molecular Dynamics; Sunnyvale, 
CA, USA). The NIDDK-anti-rBetaTSH-IC-1 and purified rat TSH were obtained through NHPP, NIDDK and AF Parlow (Harbor UCLA Medical Center, Torrance, CA, USA). L Berghman (Texas A\&M University, College Station, TX, USA) and J Proudman (Germplasm and Gamete Physiology Laboratory, USDA, Beltsville, MD, USA) kindly provided the chicken $\mathrm{LH}$ and $\mathrm{FSH}$, respectively, used in the validation of the rat TSH $\beta$ antiserum for chicken TSH $\beta$.

\section{Immunocytochemistry (ICC)}

Cell culture reagents were from Invitrogen Gibco (Grand Island, NY, USA) unless otherwise noted. Pituitaries were removed from embryos using a dissecting microscope and dissociated by trypsin digestion $(1 \mathrm{mg} / \mathrm{ml})$ in SMEM (supplemented with $0 \cdot 1 \% \mathrm{BSA}, 100 \mathrm{U} / \mathrm{ml}$ penicillin and $100 \mu \mathrm{g} / \mathrm{ml}$ streptomycin) and mechanical agitation at $37.5{ }^{\circ} \mathrm{C}$ under $5 \% \mathrm{CO}_{2} / 95 \% \mathrm{O}_{2}$ for $45 \mathrm{~min}$, triturating and gassing every $15 \mathrm{~min}$ as previously described (Porter et al. 1995). ICC was performed as previously described (Liu et al. 2003, Bossis et al. 2004), with the following changes. Rat TSH $\beta$ antiserum (NIDDK-anti-rBetaTSHIC-1) was used as the primary antiserum at 1:10 000. Cells were washed and then incubated with Vectastain $A B C$ reagent. Finally, the plate was washed again with PBS and developed using the Vectastain VIP horseradish peroxidase substrate kit. Cells were counted using an inverted light microscope and positively stained cells expressed as a percentage of all cells counted. Counting of pituitary cells began in the center of each well, and a minimum of 300 cells was evaluated for each duplicate well for each age in each replicate experiment.

\section{Whole-mount in situ hybridization}

The whole-mount in situ hybridization procedure, with modifications noted below, was performed as previously described (Bossis \& Porter 2000). Briefly, pituitaries were isolated from e19 embryos and fixed. Pituitaries were then dehydrated in an ethanol series, stored overnight, rehydrated the next day, permeabilizied with Proteinase K, and then post-fixed. Pituitaries were hybridized with digoxigenin-labelled riboprobes overnight, washed with 2 $\mathrm{x}$ and $0 \cdot 2 \mathrm{x}$ SSC, incubated with alkaline phosphataseconjugated sheep anti-digoxigenin antibody (1:2000), and developed with 4-nitro blue tetrazolium chloride and $160 \mu \mathrm{g} / \mathrm{ml}$ 5-bromo-4-chloro-3-indolylphosphate (Roche Applied Science, Indianapolis, IN, USA). The sense and antisense digoxigenin-labelled riboprobes (Boehringer Mannhein, Mannheim, Germany) were generated from a plasmid previously described (Gregory et al. 1998).

\section{Whole-mount immunocytochemistry}

Pituitaries from e19 embryos were isolated and fixed in $3.7 \%$ formaldehyde at $4{ }^{\circ} \mathrm{C}$ for $30 \mathrm{~min}$. Pituitaries were washed in PBS and dehydrated in an increasing methanol series $(50 \%, 75 \%, 95 \%$, and $100 \%)$, quenched with $0 \cdot 3 \%$ $\mathrm{H}_{2} \mathrm{O}_{2}$ in methanol for $5 \mathrm{~min}$, and stored overnight in methanol at $-20{ }^{\circ} \mathrm{C}$. Pituitaries were rehydrated the next day, permeabilized with $0.02 \%$ trypsin in $0.1 \%$ TritonX100 in PBS (PBT) for approximately $4 \mathrm{~min}$, and then the digestion was stopped by quenching in $0 \cdot 1 \%$ soybean trypsin inhibitor in PBT with $1 \mathrm{mM} \mathrm{CaCl}{ }_{2}$ (Sigma, St Louis, MO, USA) for $2 \mathrm{~min}$. Pituitaries were washed in PBT three times for $5 \mathrm{~min}$. The pituitaries were blocked in $2 \%$ NGS for $1 \mathrm{~h}$ and incubated overnight at $4{ }^{\circ} \mathrm{C}$ with the rabbit anti-rat TSH $\beta$ antiserum (1:5000) in PBS with 1\% NGS. Pituitaries were then washed six times for $5 \mathrm{~min}$ in PBT and then incubated with biotinylated anti-rabbit IgG (Vector Laboratories) for $2 \mathrm{~h}$. Pituitaries were washed in PBT three times for $5 \mathrm{~min}$, then three times for $10 \mathrm{~min}$, and incubated in Vectastain $\mathrm{ABC}$ reagent for $1 \mathrm{~h}$. Pituitaries were washed in PBT three times for $5 \mathrm{~min}$, three times for $20 \mathrm{~min}$, and then developed with Vectastain VIP horseradish peroxidase substrate kit.

\section{Plasma collection and radioimmunoassays (RIAs)}

Plasma was collected by removing the shell apical to the air sac junction, visualizing the blood vessels by moistening the inner shell membrane, nicking a vessel with a 25gauge needle, and drawing the blood into a $1 \mathrm{ml}$ syringe wetted with $0.5 \mathrm{M}$ EDTA. Blood samples were discarded if egg albumen became mixed with blood. The hematocrit was checked by visual inspection. Collected blood samples were transferred to $1.5 \mathrm{ml}$ microcentrifuge tubes on ice containing $2.5 \mu \mathrm{l}$ of $0.5 \mathrm{M}$ EDTA. Blood samples were centrifuged, and the plasma was collected and frozen at $-20{ }^{\circ} \mathrm{C}$ until assayed. RIA was performed using the Coat-A-Count Free $\mathrm{T}_{4}$ RIA kit from Diagnostic Products Corporation (Los Angeles, CA, USA) according to the manufacturer's protocol. Two different assays were used in attempts to assess plasma levels of TSH, the rat TSH RIA from American Laboratory Products Company (Windham, NH, USA) and the human TSH immunoradiometric assay from Diagnostic Products Corporation. Neither TSH assay proved effective at measuring chicken TSH.

\section{RNA extraction and Northern blotting}

Pituitaries were isolated from embryos and snap frozen in liquid nitrogen and stored at $-80{ }^{\circ} \mathrm{C}$ until RNA extraction. Pituitaries were homogenized in a $1 \mathrm{ml}$ Dounce homogenizer and RNA was isolated using TRIzol according to the manufacturer's protocol (Invitrogen Gibco). RNA was suspended in nuclease-free water, quantified by absorbance at $260 \mathrm{~nm}$, and then stored at $-80{ }^{\circ} \mathrm{C}$ until use. Approximately $5 \mu \mathrm{g}$ of total RNA/sample in RNA Loading Buffer with Ethidium Bromide (Sigma) were separated on $1 \%$ agarose- $6 \%$ formaldehyde gels with 
MOPS (Invitrogen Gibco) running buffer at $200 \mathrm{~V}$ and transferred overnight to a Zeta-Probe nylon membrane (Bio-Rad, Hercules, CA, USA) by capillary action. The RNA was cross-linked to the membrane in a UV crosslinker and pre-hybridized at $65^{\circ} \mathrm{C}$ in PerfectHyb Plus hybridization solution (Sigma) for $3 \mathrm{~h}$ in a rotating hybridization oven. ${ }^{32-} \mathrm{P}$ dCTP (Amersham Biosciences, Piscataway, N)-labelled TSH $\beta$ cDNA probes were generated by PCR using Taq polymerase (MBI Fermentas; Hanover, MD, USA). The TSH $\beta$ template: GTGGAG AAGCGGGAGTGTGCCTACTGCCTGGCCACAAC ACCACCATCTGCGCTGGATTTTGCATGACACG GGACAGCAACGGCAAGAAGCTGCTACTCAAA AGTGCTCT and primer: AGAGCACTTTTGAGTAG CAG were synthesized by Sigma-Genosys. PCR products were separated from unincorporated nucleotides by centrifugation through a Spin Column-30 (Sigma) and counted in a beta counter to determine radioactivity. Approximately $1 \times 10^{6}$ counts per minute (c.p.m.) of probe was added per $\mathrm{ml}$ of hybridization solution and allowed to hybridize overnight at $65{ }^{\circ} \mathrm{C}$. The membrane was then washed twice at low stringency with $2 \times$ SSC $(300 \mathrm{mM} \mathrm{NaCl}, 30 \mathrm{mM}$ sodium citrate) $-0 \cdot 1 \%$ SDS at room temperature. The membrane was washed with $0 \cdot 2 \mathrm{x}$ SSC $-0 \cdot 1 \%$ SDS twice at $65{ }^{\circ} \mathrm{C}$, and then twice with $0 \cdot 1 \mathrm{x}$ SSC $-0 \cdot 1 \%$ SDS at $65{ }^{\circ} \mathrm{C}$ for high stringency washes. Then, the membrane was placed between two sheets of transparency acetate inside a film cassette, allowed to expose X-ray film (X-OMAT, Eastman Kodak Co, Rochester, NY, USA) at $-80{ }^{\circ} \mathrm{C}$ for 2 days with intensification screens and the film was developed. Bands were scanned and quantified using ImageQuant software (Amersham Biosciences).

\section{Statistical analyses}

Data are reported as the least squares means \pm S.E.M. Analysis of variance (ANOVA) was used to compare means in the ontogeny experiment and the treatment effects of MMI injections (SAS version 8.02, PROC GLM or PROC MIXED procedures, SAS Institute, Cary, NC, USA). Differences were considered significant at $P<0 \cdot 05$.

\section{Results}

Validation of TSH $\beta$ antiserum by Western blotting and preabsorption in ICC

Initial experiments evaluated whether the anti-rat TSH $\beta$ antiserum could detect chicken TSH $\beta$ without crossreacting with the other pituitary glycoprotein hormones, namely $\mathrm{LH}$ and $\mathrm{FSH}$, since they all share the same $\alpha$-subunit. Chicken pituitaries were dissected from three d1, d6, and e18 embryos, and five e20 embryos, pooled and extracted. Protein from heart, liver, spleen, and muscle tissues of 3 week-old chicks was also extracted. $10 \mathrm{ng}$ of purified rat TSH, $1 \mu \mathrm{g}$ each of chicken FSH and chicken $\mathrm{LH}$, and $5 \mu \mathrm{g}$ of total protein from pituitary, heart, liver, spleen, and muscle were separated on a polyacrylamide gel and immunoblotted with the anti-rat TSH $\beta$ antiserum. Two bands of approximately $30 \mathrm{kM}_{\mathrm{r}}$ and $17 \mathrm{kM}_{\mathrm{r}}$ were detected in the chicken pituitary extract (Fig. 1). The rat TSH lane also contained 2 bands of nearly identical molecular weight. The lower band at $17 \mathrm{kM}_{\mathrm{r}}$ is presumably the $\beta$-subunit, and the higher band at $30 \mathrm{kM}_{\mathrm{r}}$ likely represents the $\alpha / \beta$ heterodimer. The antiserum only detected bands in the pituitary extracts and not in other tissues. More importantly, no cross-reaction with either chicken LH or FSH was seen, even though 100-fold more protein was tested for each than for TSH. This indicates that the antiserum recognizes chicken TSH $\beta$ and does not recognize $\mathrm{LH}$ and $\mathrm{FSH}$ or the common $\alpha$-subunit.

Next, the antiserum was further validated for use in ICC. Pituitaries from e17 embryos were dispersed and plated in a 12-well tissue culture plate. Cells were subjected to ICC using anti-TSH $\beta$ antiserum alone, antiserum preabsorbed for $3 \mathrm{~h}$ with rat TSH $(0 \cdot 1 \mu \mathrm{g} / 20 \mu \mathrm{l})$ or chicken FSH $(1 \mu \mathrm{g} / 20 \mu \mathrm{l})$. As expected, preincubation with rat TSH completely blocked staining. In contrast, preincubation with chicken FSH had no effect, confirming that the antiserum does not recognize chicken FSH or the common $\alpha$-subunit. Taken together, these two experiments indicate that the antiserum is specific for chicken TSH $\beta$ and can be used for both Western blotting and ICC.

\section{Ontogeny of thyrotrophs}

Although levels of TSH $\beta$ mRNA have been characterized during development (Gregory et al. 1998, Nakamura et al. 2004), changes in the abundance of anterior pituitary thyrotrophs have not been quantified. Pituitaries were isolated from embryos on e11, e13, e15, e17, e19, and d1 and dispersed, plated, and subjected to ICC using the anti-rat TSH $\beta$ antiserum. Results are shown in Figure 2. TSH $\beta$-containing cells comprised $0 \cdot 7 \pm 0 \cdot 1 \%$, $4 \cdot 0 \pm 0 \cdot 4 \%, \quad 5 \cdot 3 \pm 0 \cdot 4 \%, \quad 7 \cdot 0 \pm 0 \cdot 8 \%, \quad 6 \cdot 7 \pm 0 \cdot 7 \%$, and $3 \cdot 9 \pm 0 \cdot 4 \%$ of all pituitary cells on e11, e13, e15, e17, e19, and $\mathrm{d} 1$, respectively. Thus, thyrotrophs were rare on e11, and their abundance was maximal on e17 $(P<0 \cdot 01, n=4$ separate trials).

\section{Distribution of thyrotrophs within the cephalic lobe}

Early reports indicate that thyroid-stimulating activity and immunoreactive TSH are found in the cephalic lobe of the anterior pituitary gland in birds (Brasch \& Betz 1971, Radke \& Chiasson 1974, 1977, Sharp et al. 1979, Thommes et al. 1983, Murphy \& Harvey 2001). More recently, cells containing the $\alpha$-subunit but not the $\beta$-subunits for LH and FSH were found in the cephalic 


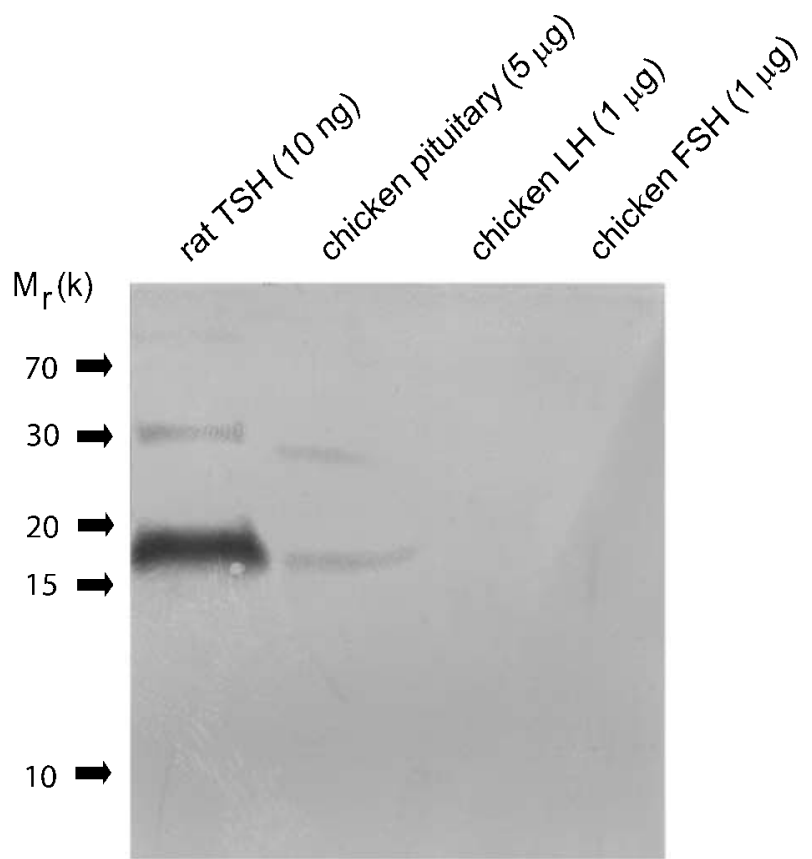

Figure 1 Analysis of antiserum specificity by Western blotting. The antiserum detected two peptide bands of similar size in both the purified rat TSH and the chicken pituitary extract lanes. No bands were observed in the lanes loaded with chicken FSH and $\mathrm{LH}$. The $30 \mathrm{kM}_{\mathrm{r}}$ band is presumably the TSH heterodimer and the $17 \mathrm{kM}_{\mathrm{r}}$ band is likely the $\beta$-subunit.

lobe in sagittal histological sections (Berghman et al. 1993). To evaluate three-dimensional distribution of thyrotrophs within the cephalic lobe prior to hatching, whole-mount in situ hybridization for TSH $\beta$ mRNA and whole-mount ICC for TSH $\beta$ peptide were performed. Pituitaries were isolated on e19, when thyrotrophs were abundant and TSH $\beta$ mRNA levels were reported to be maximal (Gregory et al. 1998). Individual pituitaries were probed with either a TSH $\beta$ antisense riboprobe or the anti-rat TSH $\beta$ antiserum. Representative results are presented in Figure 3. The presence of individual thyrotrophs is evident from the specific punctate staining. Thyrotrophs were not distributed uniformly among pituitary glands. TSH $\beta$ mRNA-containing cells were localized within the cephalic lobe of the e19 pituitary in three general patterns: a focal spot in the ventral medial region of the cephalic lobe (Fig. 3A); a "saddle" pattern extending from the ventral medial to the dorsal lateral regions of the cephalic lobe along the cephalic-caudal boundary (Fig. 3B); and an even distribution within the entire cephalic lobe (Fig. 3C). Hybridization with a sense riboprobe was negative (Fig. 3D). Whole-mount ICC produced similar results. TSH $\beta$ containing cells were found in a focal spot in the ventral region of the cephalic lobe (Fig. 3E), in a "saddle" pattern (Fig. 3F), and distributed throughout the cephalic lobe (Fig. 3 G). No staining was seen when the anti-rat TSH $\beta$
A
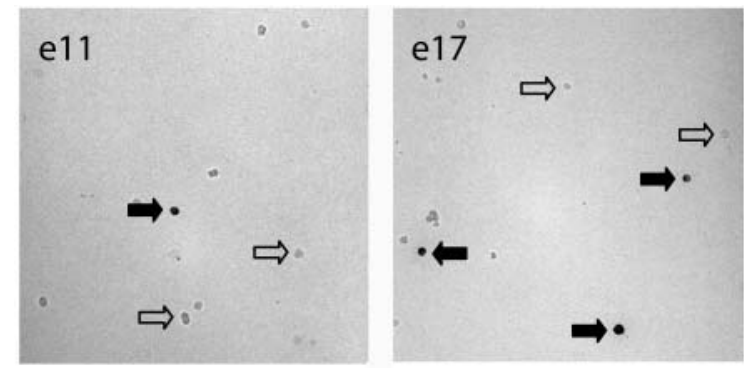

B

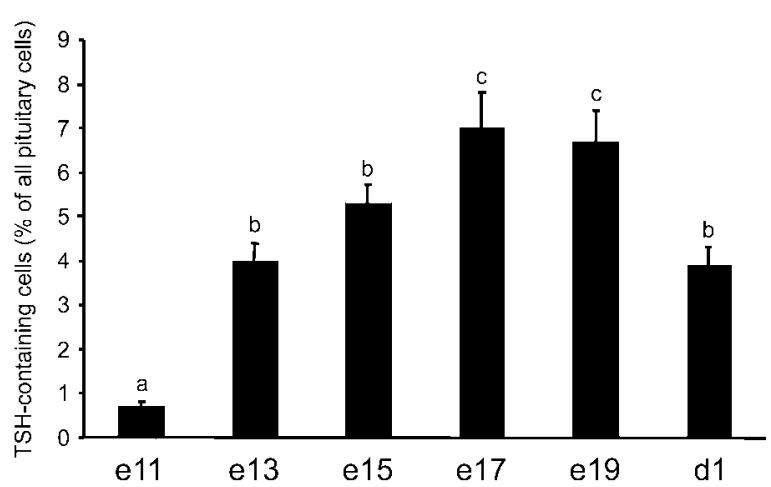

Figure 2 Ontogeny of pituitary thyrotrophs. Anterior pituitary cells were harvested at indicated ages and subjected to ICC for TSH $\beta$. Representative results from e11 and e17 are shown (A).

TSH $\beta$-positive cells are identified by closed arrows and some of the TSH $\beta$-negative cells are denoted with open arrows. Quantitative results are reported as the percentage of TSH $\beta$ positive cells and are the least squares means of four independent replicate trials (B). Data were analyzed by ANOVA, followed by Duncan's multiple range test (SAS). Values denoted by different letters are significantly different from one another $(P<0 \cdot 05)$. Vertical bars represent the standard errors of the means.

antiserum was omitted (Fig. 3H). Thus, results from both whole-mount in situ hybridization and whole-mount ICC indicate heterogeneous distribution of thyrotrophs within the cephalic lobe. To confirm cephalic lobe localization of thyrotrophs, the cephalic and caudal distal ends (approximately one third) of anterior pituitaries were isolated in situ within the sella turcica on e19, as previously described (Lopez et al. 1995). By using only the caudal or cephalic third of each individual pituitary, separation of the lobes was ensured. Pools were then made of caudal and cephalic lobes from at least three embryos for each replicate experiment. Growth hormone $(\mathrm{GH})$ - and prolactin (PRL)-containing cells were identified by ICC, as described previously (Lopez et al. 1995, Liu et al. 2003, Bossis et al. 2004). The lobes were then dispersed, plated, and subjected to ICC for TSH $\beta$, GH (a caudal lobe marker), and PRL (a cephalic lobe marker). TSH $\beta$ - and PRLcontaining cells were found among cells isolated from the cephalic lobe, while GH-positive cells were predominantly found in the caudal lobe (Fig. 4). Taken together, these findings from single cell ICC, whole-mount ICC, and whole-mount in situ hybridization confirm that 

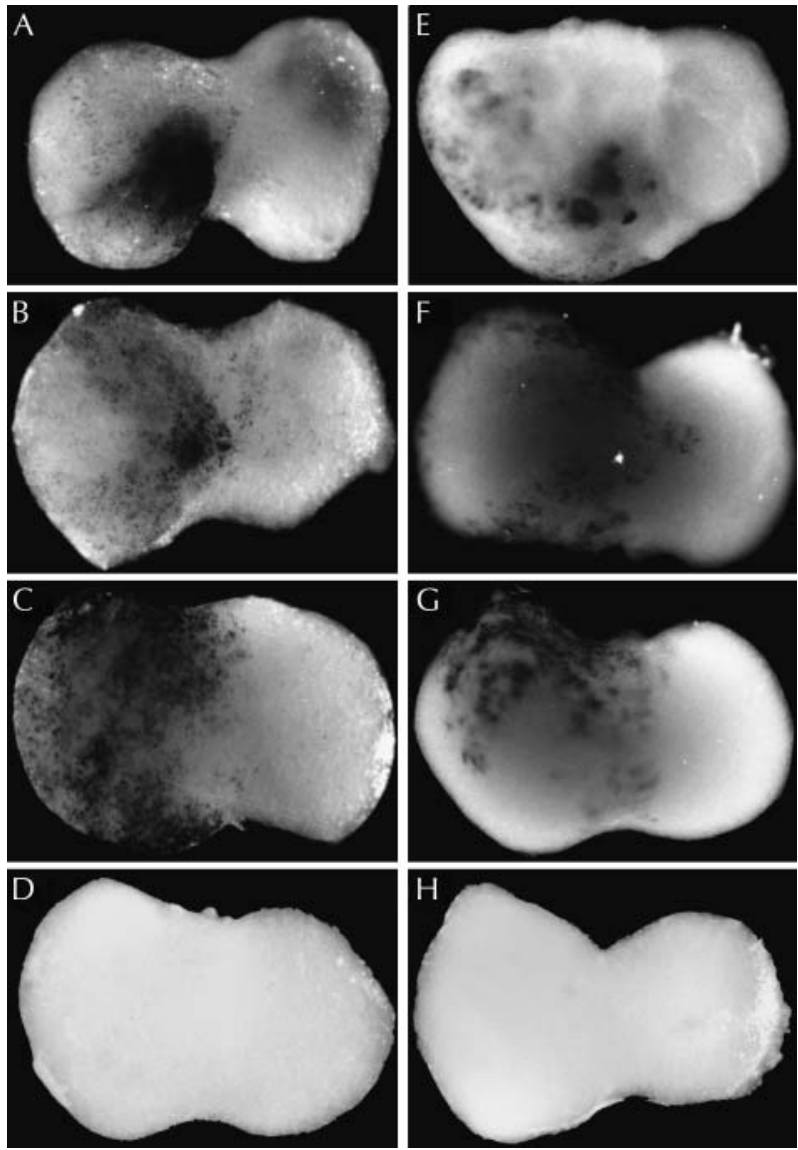

Figure 3 Localization of thyrotrophs within the cephalic lobe of the anterior pituitary. Embryonic day 19 pituitaries were isolated and subjected to either whole-mount in situ hybridization (ISH) for TSH $\beta$ mRNA (A-D) or immunocytochemistry (ICC) for TSH $\beta$ peptide $(\mathrm{E}-\mathrm{H})$. Pituitaries in all fields are oriented with the cephalic lobe to the left. A, B, and C show three patterns of ISH staining for TSH $\beta$ mRNA within the cephalic lobe. E, F, and G show three similar patterns with ICC for TSH $\beta$ peptide performed on different pituitaries. D is ISH with a sense strand probe control. $\mathrm{H}$ is ICC with no primary antibody.

thyrotrophs are localized to the cephalic lobe of the chicken anterior pituitary gland. Furthermore, results from whole-mount ICC and in situ hybridization indicate that thyrotroph distribution is heterogeneous within the cephalic lobe among individual embryos, with a "saddleshaped" pattern being the most common distribution pattern seen on e19.

Effects of methimazole on thyroid-stimulating hormone in vivo

We reported previously that TSH $\beta$ mRNA levels and plasma thyroid hormone levels increase prior to hatching (Gregory et al. 1998). We also found that $\mathrm{T}_{3}$ could suppress TSH $\beta$ mRNA levels in cultures of e19 pituitary cells, indicating the potential for feedback regulation.

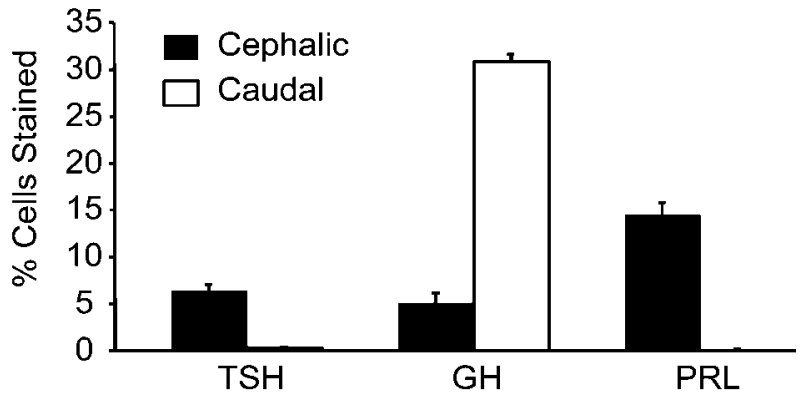

Figure 4 Confirmation of thyrotroph localization to the cephalic lobe. Pools of cephalic and caudal lobes from e19 pituitaries were dispersed and subjected to ICC for TSH $\beta, \mathrm{GH}$, and prolactin. Cells containing TSH $\beta$ (thyrotrophs) and cells containing prolactin (lactotrophs) were found in the cephalic lobe, while cells containing growth hormone were found in the caudal lobe. Vertical bars represent the standard errors of means $(n=3$ separate experiments)

However, the contribution of negative feedback from endogenous thyroid hormones on TSH $\beta$ mRNA levels and pituitary TSH content during this critical period of embryonic development has not been reported. Endogenous thyroid hormone production in the chick embryo was suppressed with MMI injections on e13, e15, e17, and e19. MMI-injected embryos were less developed than the controls and did not hatch. This is consistent with reported effects of MMI on chicken embryos by a continuous flow delivery system (Iqbal et al. 1987). To confirm MMI suppression of thyroid hormones, a RIA for free $T_{4}$ was performed. In control embryos, $\mathrm{T}_{4}$ increased more than 6-fold, from $0.025 \pm 0.004 \mathrm{ng} / \mathrm{dl}$ on $\mathrm{e} 17$, to 0.072 $\pm 0.03 \mathrm{ng} / \mathrm{dl}$ on e19, to $0 \cdot 162 \pm 0.044 \mathrm{ng} / \mathrm{dl}$ on $\mathrm{d} 1$ (Fig. 5). $T_{4}$ was undetectable in the plasma of MMI-treated embryos. Next, identical experiments were performed, and pituitaries were collected and pooled from five to seven embryos for each treatment on e17, e19, and d1. Total RNA was isolated from pituitaries of MMI-injected and control embryos on e17, e19, and d1, and analyzed by northern blotting. As seen in Fig. 6, TSH $\beta$ mRNA levels were increased by MMI treatment $(n=6$ replicate experiments; $P<0 \cdot 01$; across all ages), with significant differences between MMI and control groups found on e19 and d1 $(P<0 \cdot 05)$. Levels of TSH $\beta$ mRNA in control groups were: e17, $1.61 \pm 0.40$ R.D.U. (relative densitometric units; ratio of TSH $\beta / \beta$-actin mRNA in arbitrary densitometric units); e19, 1.21 \pm 0.42 R.D.U.; d1, 1.24 $\pm 0 \cdot 48$ R.D.U. Levels of TSH $\beta$ mRNA in MMI-treated groups were: e17, 2.00 \pm 0.40 R.D.U.; e19, 2.07 \pm 0.40 R.D.U.; d1, $2.58 \pm 0.42$ R.D.U. These results indicate that TSH $\beta$ gene expression during perinatal development of the chick is under negative feedback regulation from endogenous thyroid hormones. Next, experiments were performed to determine the effect of MMI on TSH $\beta$ protein levels. Protein was extracted from pituitaries pooled from five to 


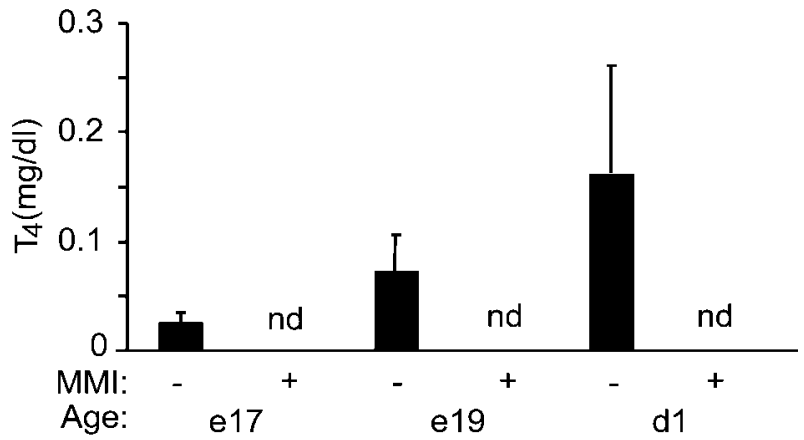

Figure 5 Radioimmunoassay for free $\mathrm{T}_{4}$. Blood was collected in tubes containing EDTA. RIA for free $\mathrm{T}_{4}$ was performed on individual plasma samples ( $n=5$ for each group). Means and standard errors for the control groups are presented. $\mathrm{T}_{4}$ was not detectable in any of the plasma samples from MMI-treated embryos. The detection limit of the RIA was $0.02 \mathrm{ng} / \mathrm{dl}$. nd, not detected.

seven MMI-injected and control embryos on e17, e19, and $\mathrm{d} 1$, and analyzed by Western blotting (Fig. 7). Control pituitaries contained more TSH $\beta$ protein than the MMI treated groups $(n=3$ replicate experiments; $P<0 \cdot 01$; across all ages), with significant differences between MMI and control groups found on e17 and e19 $(P<0 \cdot 05)$. TSH $\beta$ protein levels in R.D.Us (intensity of the $17 \mathrm{kM}_{\mathrm{r}}$ band normalized to the $17 \mathrm{kM}_{\mathrm{r}}$ band of rat TSH $\beta$ standard in arbitrary densitometric units) for the control groups were: e17, $0.336 \pm 0.08$ R.D.U.; e19, 0.350 \pm 0.08 R.D.U.; d1, $0 \cdot 246 \pm 0.08$ R.D.U. Levels of TSH $\beta$ protein in MMI-treated pituitaries were: e17, 0·108 \pm 0.08 R.D.U.; e19, 0.090 $\pm 0 \cdot 08$ R.D.U.; d1, 0.140 $\pm 0 \cdot 08$ R.D.U. Thus, inhibition of endogenous thyroid hormone synthesis resulted in decreased pituitary TSH $\beta$ protein content.

Levels of TSH $\beta$ protein have not been measured directly in chicken plasma, but in mammals MMI treatment increases levels of TSH in the blood (Rondeel et al. 1992). The fact that the MMI-treated pituitaries contained less TSH $\beta$ peptide than control pituitaries would argue for increased secretion into the blood, consistent with the mammalian model. We attempted to confirm increased levels of plasma TSH by RIA and by western blotting of plasma samples. Unfortunately, our attempts to develop a valid RIA for chicken TSH $\beta$ using the rat TSH $\beta$ antiserum and rat TSH as tracer were unsuccessful. Samples of chicken plasma and pituitary extracts failed to displace the rat TSH tracer, presumably due to the much greater affinity of the antiserum for the homologous antigen than for the heterologous chicken TSH $\beta$ (data not shown). Two commercially available immunoassays for mammalian TSH also failed to detect chicken TSH. Western blotting of plasma samples was hampered by large amounts of albumin present, and prior immunoprecipitation of TSH $\beta$ resulted in substantial non-specific staining of immunoglobulin fragments in the same molecular weight
A

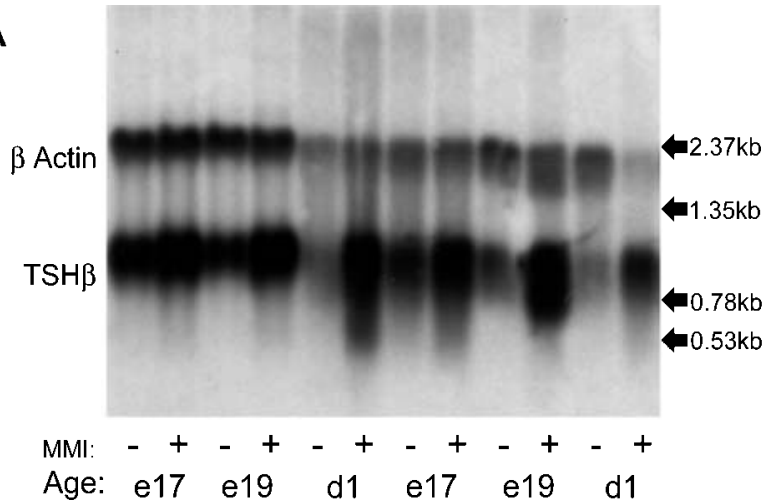

B

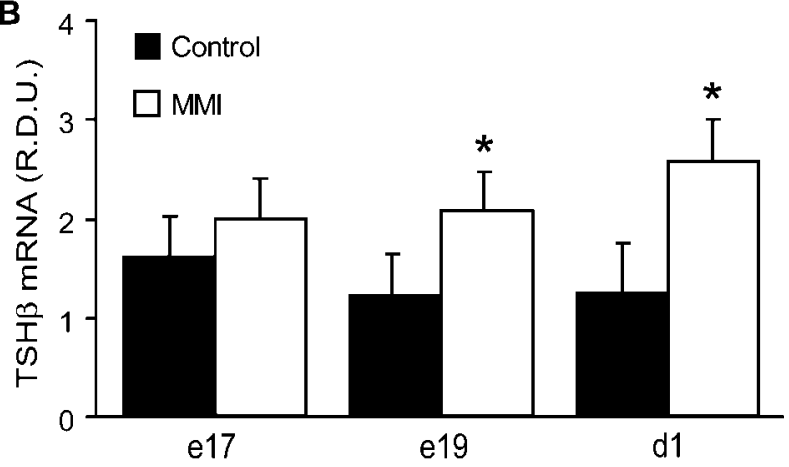

Figure 6 Effect of $\mathrm{MMI}$ on TSH $\beta$ mRNA levels. Pituitaries were collected and pooled from five to seven embryos for each group in each replicate experiment. Total RNA was isolated and analyzed ( $5 \mu \mathrm{g} / \mathrm{sample}$ ) by northern blotting (A). Arrows indicate locations of standards in an RNA ladder. Autoradiographs were scanned and bands quantified using ImageQuant software (B). Least squares means and standard errors of six independent experiments are shown. Levels of TSH $\beta$ mRNA (in arbitrary densitometric units) were normalized to $\beta$-actin mRNA to yield relative densitometric units (R.D.U.). Results were compared using mixed-model ANOVA (SAS Institute). *, $P<0 \cdot 05$ compared with control at that age.

range as TSH $\beta$ (results not shown). Thus, we were unable to directly confirm that inhibition of endogenous thyroid hormone synthesis resulted in increased pituitary TSH secretion into the blood.

\section{Discussion}

An increase in thyroid hormone levels is essential for hatching and the transition to posthatch endothermic life during chick development. Despite this critical role for the HPT axis, relatively little is known about the regulation of pituitary thyrotrophs during this period. We reported previously that pituitary TSH $\beta$ mRNA increases prior to hatching (Gregory et al. 1998). However, it was not known whether this increase was due to greater levels of TSH $\beta$ gene expression in existing thyrotrophs or due to an increase in the number of thyrotrophs. 
A

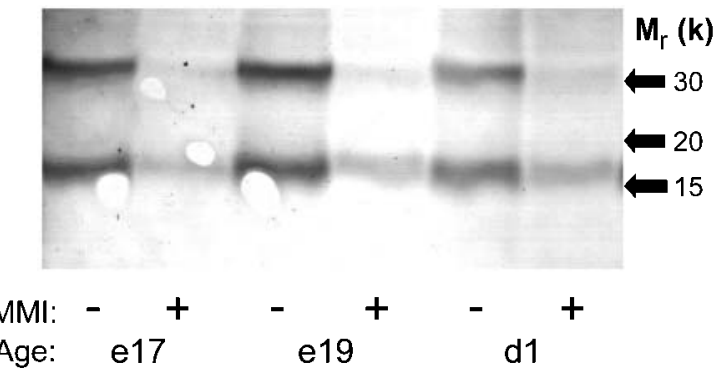

B

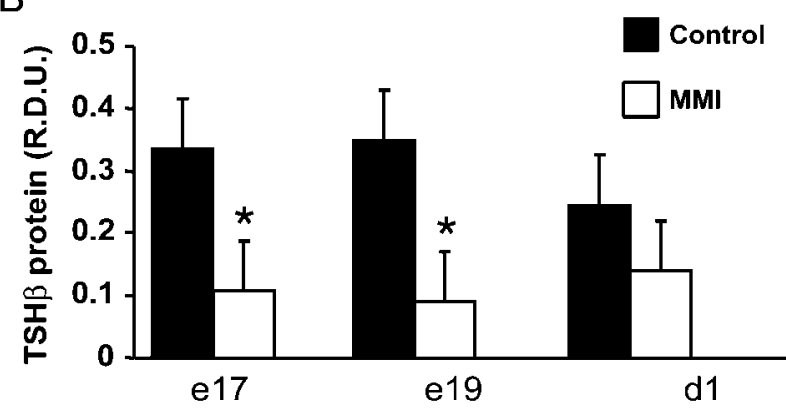

Figure 7 Effect of $\mathrm{MMI}$ on pituitary TSH $\beta$ protein levels. Pituitaries were collected and pooled from five to seven embryos for each group in each replicate experiment. Total protein was isolated and analyzed ( $20 \mu \mathrm{g} / \mathrm{sample})$ by Western blotting (A). Filters were scanned and the $17 \mathrm{kM}_{\mathrm{r}}$ bands quantified using ImageQuant software (B). Least squares means and standard errors of three independent experiments are shown. Levels of TSH $\beta$ peptide were normalized to $5 \mathrm{ng}$ of rat TSH $\beta$ standard in each western blot and compared using mixed-model ANOVA (SAS Institute). ${ }^{*}, P<0 \cdot 05$ compared with control at that age.

Nakamura et al. (2004) recently reported that thyrotroph cell density in sagittal sections increased during development. However, absolute numbers of TSH cells could not be determined from this type of analysis. The ontogeny of thyrotrophs during chick embryonic development was quantified in the present study. TSH $\beta$-positive cells were less than $1 \%$ of the pituitary population on e11, the earliest day pituitaries were examined. The percentage of thyrotrophs increased several fold on e13 and peaked on e17 and $\mathrm{e} 19$. The increase in the number of TSH $\beta$-containing cells between e11 and e13 follows with the maturation of the HPT axis (Thommes 1987). The percentage of thyrotrophs then decreased by $\mathrm{d} 1$, presumably with the appearance of cells from later differentiating cell lineages such as somatotrophs and lactotrophs. We have reported that pituitary GH cells become a significant population on e16 and that pituitary PRL cells first appear on e17 (Porter et al. 1995, Woods \& Porter 1998). Thus, the peak number of thyrotrophs occurs in the days just prior to hatching. This is the period in development when the animal transitions from ectothermy to endothermy after hatching. During incubation, the temperature of the embryo is maintained by the nesting hen or a commercial incubator; after hatching, the chicks regulate their own body temperature. Our present findings indicate that the abundance of thyrotrophs increases in preparation for hatching and the transition to an endothermic existence.

Thyrotrophs have been localized in the cephalic lobe of the anterior pituitary by ICC on histology sections and by assessment of biological activity in tissue extracts (Brasch \& Betz 1971, Radke \& Chiasson 1974, 1977, Sharp et al. 1979, Thommes et al. 1983, Berghman et al. 1993, Murphy \& Harvey 2001, 2002, Iwasawa et al. 2002, Nakamura et al. 2004). However, the three-dimensional distribution of thyrotrophs within the cephalic lobe of the anterior pituitary has not been determined. To accomplish this, in situ hybridization and ICC were performed in the present study on whole-mounted pituitary glands. As expected, the cTSH $\beta$ riboprobe detected TSH $\beta$ mRNA in the cephalic lobe of the anterior pituitary. Interestingly, different patterns of expression were noted. In some pituitaries, the thyrotrophs were localized to a small region in the medial ventral area of the cephalic lobe; in other pituitaries, cells throughout the entire cephalic lobe were stained for TSH $\beta$ mRNA. There was also a "saddleshaped" staining pattern observed, extending from the medial ventral region of the cephalic lobe to the lateral dorsal regions along the cephalic-caudal boundary of the anterior pituitary. Similar patterns were seen when ICC for TSH $\beta$ protein was performed on whole-mounted pituitaries. The saddle-shaped pattern was most commonly observed. These two sets of experiments, probing for both TSH $\beta$ mRNA and TSH $\beta$ peptide, prove conclusively that the thyrotrophs are localized to the cephalic lobe of the chick anterior pituitary. This is consistent with the reports of immunopositive cells in cephalic sections and homogenates using anti-peptide and heterologous antisera (Sharp et al. 1979, Thommes et al. 1983, Mikami 1986, Murphy \& Harvey 2001, 2002, Iwasawa et al. 2002, Sasaki et al. 2003, Nakamura et al. 2004). These findings also indicate that the distribution of thyrotrophs is heterogeneous among individual embryos at this stage of development. Interestingly, in mice a population of thyrotrophs exists transiently during development at the rostral tip of the pituitary in addition to the caudomedial, permanent thyrotrophs (Lin et al. 1994). It is unknown whether this is also true in chickens, as only pituitaries on e19 were examined. However, the different patterns of thyrotroph localization noted in the present study using both ICC and in situ hybridization make it tempting to speculate that thyrotroph differentiation during chick development initiates in the ventral medial region of the cephalic lobe and proceeds in a dorsal and then rostral fashion so that thyrotrophs are eventually dispersed throughout the cephalic lobe of the anterior pituitary gland.

Classically, thyroid hormones are thought to feed back to suppress the release of TSH from the pituitary. However, this has not been determined during chick embry- 
onic development. $T_{4}$ and $T_{3}$ secretion increases prior to hatching (Gregory et al. 1998). Our finding of increased numbers of thyrotrophs and previous findings of elevated TSH $\beta$ mRNA levels in the pituitary at the end of embryonic development (Gregory et al. 1998) raises the possibility that TSH production is not regulated by negative feedback from endogenous thyroid hormones during this period of development. To explore this possibility, endogenous thyroid hormone synthesis was suppressed by injecting eggs with MMI. Effectiveness of MMI injections was confirmed by measuring plasma levels of $\mathrm{T}_{4} \cdot \mathrm{T}_{4}$ was below the limit of detection for all three ages of MMItreated embryos assayed. The control embryos showed increasing levels of $\mathrm{T}_{4}$ prior to hatching, as expected. MMI treatment increased levels of TSH $\beta$ mRNA in the pituitary. This increase in TSH $\beta$ mRNA suggests that TSH $\beta$ gene expression is normally under negative feedback by thyroid hormones during this period of development. Somewhat surprisingly, control pituitaries contained more TSH $\beta$ protein than the MMI-treated pituitaries. Thus, MMI-treated pituitaries contain more TSH $\beta$ mRNA but less TSH $\beta$ protein. This finding is likely due to increased secretion of TSH protein by the thyrotrophs into the bloodstream in MMI-treated embryos. The pituitary, therefore, is depleted of TSH as compared with control embryos. Alternatively, this may indicate that TSH $\beta$ protein synthesis was decreased in response to MMI treatment. However, given that TSH $\beta$ mRNA levels were increased by MMI, this possibility would seem unlikely. Similar findings of decreased staining intensities in purported thyrotrophs were noted when older, posthatch birds were fed MMI (Sharp et al. 1979, Berghman et al. 1993). Taken together, the increase in TSH $\beta$ mRNA levels in combination with diminished pituitary TSH $\beta$ protein content in MMI-treated embryos clearly indicate that pituitary thyrotrophs are normally under tonic inhibition by endogenous thyroid hormones prior to hatching. Furthermore, these findings indicate that the increase in thyroid hormone levels, in pituitary thyrotrophs, and in pituitary TSH $\beta$ mRNA and protein levels prior to hatching are not due to a lack of negative feedback inhibition within the HPT axis. Rather, our findings suggest that the increase in thyroid hormone levels critical to hatching and the transition to endothermic life is driven either by an autonomous increase in pituitary thyrotrophs and TSH secretion or by an increase in hypothalamic stimulation of pituitary thyrotrophs. Levels of hypothalamic TRH are known to increase prior to hatching (Geris et al. 1998, 1999), supporting the notion that ultimately the hypothalamus controls the metabolic jump to endothermic life.

In conclusion, we report that the number of thyrotrophs increases dramatically between $\mathrm{e} 11$ and hatching, that their distribution within the cephalic lobe is heterogeneous on e19 but most commonly in a saddle-shaped pattern, and that TSH $\beta$ gene expression and protein secretion are regulated by negative feedback from endogenous thyroid hormones during the perinatal period of chick embryonic development, when the transition to endothermic life occurs. These findings indicate that the increased activity of the HPT axis necessary for hatching and endothermic life is not due to the absence of thyroid hormone negative feedback on pituitary TSH production.

\section{Acknowledgements}

This work was supported by USDA Grants 00-0352069463 and 03-035206-12836 to TE P. The authors declare that there is no conflict of interest that would prejudice the impartiality of this scientific work.

\section{References}

Berghman LR, Darras VM, Chiasson RB, Decuypere E, Kuhn ER, Buyse J \& Vandesande F 1993 Immunocytochemical demonstration of chicken hypophyseal thyrotropes and development of a radioimmunological indicator for chicken TSH using monoclonal and polyclonal homologous antibodies in a subtractive strategy. General and Comparative Endocrinology 92 189-200.

Bossis I \& Porter TE 2000 Ontogeny of corticosterone-inducible growth hormone-secreting cells during chick embryonic development. Endocrinology 141 2683-2690.

Bossis I, Nishimura S, Muchow M \& Porter TE 2004 Pituitary expression of type I and type II glucocorticoid receptors during chicken embryonic development and their involvement in growth hormone cell differentiation. Endocrinology 145 3523-3531.

Brasch M \& Betz TW 1971 The hormonal activities associated with the cephalic and caudal regions of the cockerel pars distalis. General and Comparative Endocrinology 16 241-256.

DeGroef B, Geris KL, Manzano J, Bernal J, Millar RP, Abou-Samra AB, Porter TE, Iwasawa A, Kuhn ER \& Darras VM 2003 Involvement of thyrotropin-releasing hormone receptor, somatostatin receptor subtype 2 and corticotropin-releasing hormone receptor type 1 in the control of chicken thyrotropin secretion. Molecular and Cellular Endocrinology 203 33-39.

Geris KL, Kotanen SP, Berghman LR, Kuhn ER \& Darras VM 1996 Evidence of a thyrotropin-releasing activity of ovine corticotropin-releasing factor in the domestic fowl (Gallus domesticus). General and Comparative Endocrinology 104 139-146.

Geris KL, Berghman LR, Kuhn ER \& Darras VM 1998 Pre- and posthatch developmental changes in hypothalamic thyrotropin-releasing hormone and somatostatin concentrations and in circulating growth hormone and thyrotropin levels in the chicken. Journal of Endocrinology 159 219-225.

Geris KL, D'Hondt E, Kuhn ER \& Darras VM 1999 Thyrotropin-releasing hormone concentrations in different regions of the chicken brain and pituitary: an ontogenetic study. Brain Research 818 260-266.

Geris KL, DeGroef B, Kuhn ER \& Darras VM 2003a In vitro study of corticotropin-releasing hormone-induced thyrotropin release: ontogeny and inhibition by somatostatin. General and Comparative Endocrinology 132 272-277.

Geris KL, DeGroef B, Rohrer S, Gleesen S, Kuhn E \& Darras V $2003 b$ Identification of somatostatin receptors controlling growth hormone and thyrotropin secretion in the chicken using receptor subtype specific agonists. Journal of Endocrinology 177 279-286.

Gregory CC, Dean CE \& Porter TE 1998 Expression of chicken thyroid-stimulating hormone $\beta$-subunit messenger ribonucleic acid during embryonic and neonatal development. Endocrinology 139 474-478. 
Iqbal A, Decuypere E, Kuhn ER, Schneider R, Verheyen G \& Huybrechts LM 1987 The influence of methimazole on the thyrotrophic and peripheral activity of thyrotrophin and thyrotrophin-releasing hormone in the chick embryo and growing chicken. Domestic Animal Endocrinology 4 291-298.

Iwasawa A, Nakayama H, Yamamoto Y, Doi O, Nakamura T \& Kato Y 2002 Specific anti-peptide antibody to $\beta$ subunit of chicken thyrotropin: production and characterization. Journal of Reproduction and Development 48 197-204.

Kameda Y, Miura M \& Ohno S 2000 Expression of the common $\alpha$-subunit mRNA of glycoprotien hormones during the chick pituitary organogenesis, with special reference to the pars tuberalis. Cell and Tissue Research 299 71-80.

Kuhn ER, Decuypere E, Iqbal A, Luysterborgh D \& Michielsen R 1988 Thyrotropic and peripheral activities of thyrotropin and thyrotropin-releasing hormone in the chick embryo and adult chickens. Hormone and Metabolic Research 20 158-162.

Lin SC, Li S, Drolet DW \& Rosenfeld MG 1994 Pituitary ontogeny of the Snell dwarf mouse reveals Pit-1-independent and Pit-1-dependent origins of the thyrotrope. Development $\mathbf{1 2 0}$ 515-522.

Liu L, Dean CE \& Porter TE 2003 Thyroid hormones interact with glucocorticoids to affect somatotroph abundance in chicken embryonic pituitary cells in vitro. Endocrinology 144 3836-3841.

Lopez ME, Hargis BM, Dean CE \& Porter TE 1995 Uneven regional distributions of prolactin-and growth hormone-secreting cells and sexually dimorphic proportions of prolactin secretors in the adenohypophysis of adult chickens. General and Comparative Endocrinology 100 246-254.

McNabb FMA 2000 Thyroids. In Sturkie's Avian Physiology, pp 461-471. Ed. GC Whittow. San Diego: Academic Press.

Mikami MI 1986 Immunocytochemistry of the avian hypothalamus and adenohypophysis. International Review of Cytology 103 189-248.

Murphy AE \& Harvey S 2001 Extrapituitary $\beta$ TSH and GH in early chick embryos. Molecular and Cellular Endocrinology 185 161-171.

Murphy AE \& Harvey S 2002 Extrapituitary TSH in early chick embryos: Pit-1 dependence? Journal of Molecular Neuroscience 18 77-87.

Nakamura K, Iwasawa A, Kidokoro H, Komoda M, Zheng J, Maseki Y, Inoue K \& Sakai T 2004 Development of thyroid-stimulating hormone beta subunit-producing cells in the chicken embryonic pituitary gland. Cells Tissues Organs 177 21-28.

Porter TE, Couger GS, Dean CE \& Hargis BM 1995 Ontogeny of growth hormone $(\mathrm{GH})$-secreting cells during chicken embryonic development: Initial somatotrophs are responsive to GH-releasing hormone. Endocrinology 136 1850-1856.

Radke WJ \& Chiasson RB 1974 Thyroid-stimulating hormone location in the chicken pars distalis. Journal of Endocrinology $\mathbf{6 0}$ 187-188.

Radke WJ \& Chiasson RB 1977 In vitro regulation of chicken thyrotropes. General and Comparative Endocrinology 31 175-182.

Rondeel J, Greef WD, Klootwijk W \& Visser T 1992 Effects of hypothyroidism on hypothalamic release of thyrotropin-releasing hormone in rats. Endocrinology 130 651-656.

Sasaki F, Doshita A, Matsumoto Y, Kuwahara S, Tsukamoto Y \& Agawa K 2003 Embryonic development of the pituitary gland in the chick. Cells Tissues Organs 173 65-74.

Scanes CG 1974 Some in vitro effects of synthetic thyrotropin releasing factor on the secretion of thyroid stimulating hormone from the anterior pituitary gland of the domestic fowl. Neuroendocrinology 15 $1-9$.

Sharp PJ, Chiasson RB, Tounsy MME, Klandorf H \& Radke WJ 1979 Localization of cells producing thyroid stimulating hormone in the pituitary gland of the domestic drake. Cell and Tissue Research 198 53-63.

Thommes RC 1987 Ontogenesis of thyroid function and regulation in the developing chick embryo. Journal of Experimental Zoology Suppl 1 273-279.

Thommes RC, Martens JB, Hopkins WE, Caliendo J, Sorrentino MJ \& Woods JE 1983 Hypothalamo-adenohypophyseal-thyroid interrelationships in the chick embryo. IV. Immunocytochemical demonstration of TSH in the hypophyseal pars distalis. General and Comparative Endocrinology 51 434-443.

Woods KL \& Porter TE 1998 Ontogeny of prolactin-secreting cells during chick embryonic development: effects of vasoactive intestinal peptide. General and Comparative Endocrinology 112 240-246.

Received 28 September 2004 Accepted 11 November 2004 